\title{
Recurrent artery of Heubner - morphological variations
}

Discipline of anatomy, Department I - preclinical disciplines, Faculty of medicine, University "Ovidius" Constanţa

\begin{abstract}
Recurrent artery of Heubner (RAH) is the largest and most constant perforating branch of anterior cerebral artery. It supplies blood to the medial portion of the orbitofrontal cortex, the anterior portion of the caudate nucleus, the anterior third of the putamen, the external segment of the globus pallidus, and the anterior crus of the internal capsule The anatomical variation of RAH is related to its traject, number, presence, or absence, and the diverse origin from ACA is of considerable clinical impact mainly from the point of view of the surgical procedures involving the anterior portion of the circle of Willis or the topographically related structures. The present study aimed to demonstrate vascular anatomy of this RAH and its variation.

The study included 60 human cadaveric brains fixed in the formalin and examined under operating microscope. 22 freshly harvested human cadaveric brains, injected with a polymer (Technovit 7143), a partial coroded and also we have consulted 30 digital subtraction angiograms.

We have evaluated the origin, traject and caliber of recurrent artery of Heubner, our results were compared with other anatomical studies published. The most obvious finding was the great variability of its origin but in $91 \%$ of the cases it was in the range of $2 \mathrm{~mm}$ around
\end{abstract}

\section{Iliescu D.M.}

Department of Anatomy, Faculty of medicine, University "Ovidius" Constanţa, Romania

Aleea Universitatii, Nr. 1, Campus B

Constanţa, Romania

dan@anatomie.ro anterior communicating artery, that could be harmed during aneurismal clipping.

The RAH is commonly arising from ACA-ACoA junction. This portion of the circle of Willis is the place of many anatomical variations and malformations. The vessel can be absent, single, or multiple, and its diameter is highly variable. The awareness of these distinct anatomical and morphometric variations of the RAH is essential in planning the neurosurgical procedures in the anterior part of the circle of Willis to avoid the unexpected neurological complications.

Key words: recurrent artery of Heubner (RAH) anterior cerebral artery (ACA), origin

\section{Introduction}

Recurrent artery of Heubner (RAH) is the largest and most constant perforating branch of anterior cerebral artery. It was first described by the German pediatrician Johann Otto Leonhard Heubner in 1872, when described a small artery arising from the base of the anterior cerebral artery and supplying blood to the head of the corpus striatum $[1,2]$. Since then many studies had as subject of interest this vascular segment, because of its clinical importance in surgical cure of anterior communicating artery aneurysms.

$\mathrm{RAH}$ is a branch of the anterior cerebral artery 
(ACA). The anterior cerebral artery (ACA) is divided into 5 segments: A1 - precommunicating portion, from its origin from internal carotid artery till the anterior communicating artery $(\mathrm{ACoA})$; $\mathrm{A} 2$ - from the anterior communicating artery (ACoA) until the callosomarginal artery; A3 - distal to callosomarginal artery, A4 - horizontal part of the artery that surrounds the knee of corpus callosum till the coronary suture, A5-coresponds to pericallosal artery [3]. The recurrent artery of Heubner (RAH) is usually the largest of the perforating medial lenticulostriate arteries branching from ACA. The RAH supplies blood to the medial portion of the orbitofrontal cortex, the anterior portion of the caudate nucleus, the anterior third of the putamen, the external segment of the globus pallidus, and the anterior crus of the internal capsule $[1,2,4,5,6]$. The artery also supplies the olfactory region, the anterior hypothalamus, the nucleus accumbens, parts of the uncinate fasciculus, the diagonal band of Broca, and the basal nucleus of Meynert [3,5,7,8,9].

The anatomical variation of RAH is related to its traject, number, presence, or absence, and the diverse origin from ACA is of considerable clinical impact mainly from the point of view of the surgical procedures involving the anterior portion of the circle of Willis or the topographically related structures. The present study aimed to demonstrate vascular anatomy of this RAH and its variation.

\section{Material and Methods}

The study included 60 human cadaveric brains that were collected with no gross brain pathology from routine brain autopsy at Constanta Clinical Emergency County Hospital. Some of the specimens were fixed in the formalin and examined under operating microscope. Following their removal from the cranial cavity, they were fixed in solution of formalin. The arachnoid was carefully removed from the base of each brain to assess the circle of Willis and its branches. The dissection was started from internal carotid artery (ICA) bifurcation to ACA1, ACoA, $\mathrm{ACA} 2$ and $\mathrm{RAH}$. The terminations in the anterior perforated substance were followed along the course of RAH. Other cases included 22 freshly harvested human cadaveric brains, that after a careful dissection have been injected with a polymer (Technovit 7143), a partial coroded to be able to see the arterial branches. The vascular anatomy of the ACoA, RAH, and their variations were documented with a digital camera. The images were calibrated by applying a plastic ruler in situ. According to these data I was able to determine the image distances in metric unit by calculating the pixel differences. The RAH point of origin, possible abnormalities or variations and its external diameter were evaluated and analyzed in each brain. Also we have consulted 30 digital subtraction angiograms.

\section{Results}

The RAH it was identified as rising from horizontal segment of ACA, A1, in 12 cases, $10.7 \%$ (Figures 1 and 2), from those 6 were situated at $1 \mathrm{~mm}$ proximal to ACoA, 5 of them at $2 \mathrm{~mm}$ from ACoA and in 1 case was at $3 \mathrm{~mm}$. In 60 cases, $53.5 \%$ its origin was at the junction of $\mathrm{A} 1$ with $\mathrm{A} 2$ segments, in the immediate proximity of ACoA (Fig.3). In 31 cases, $27.6 \%$ RAH was rising from proximal part of A2 segment (Figure 4), 16 had they origin at $1 \mathrm{~mm}$ distal of ACoA, 10 of the cases the point of origin was situated at $2 \mathrm{~mm}$ from $\mathrm{ACoA}$, in 3 cases at $3 \mathrm{~mm}$ from $\mathrm{ACoA}$ and 2 cases at $4 \mathrm{~mm}$ from ACoA. 


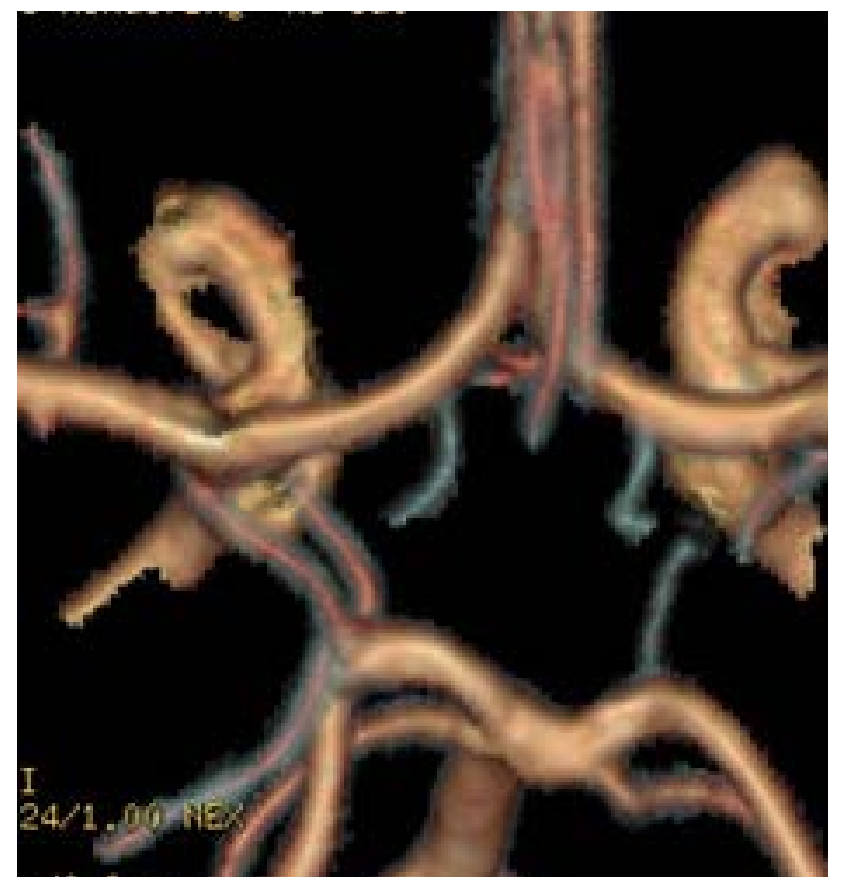

Figure 1 - RAHs originating from ACA A1, bilateraly

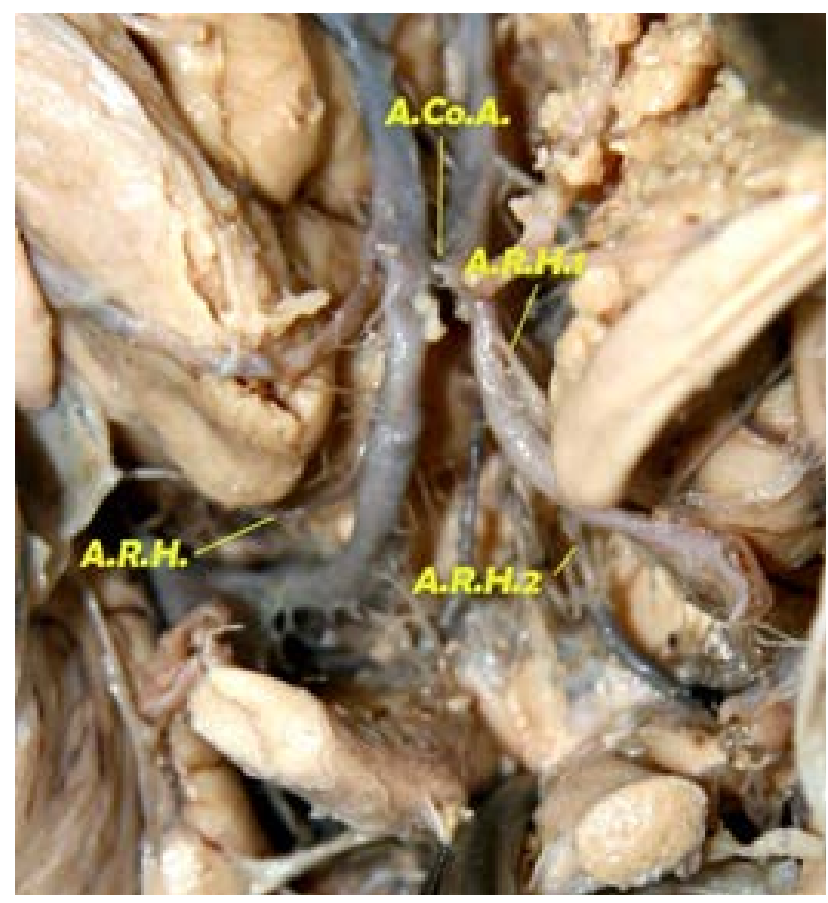

Figure 2 - RAHs originating from ACA A1, bilateraly with $2 R A H s$ on the left side (ARH - recurent artery of Heubner, AcoA - Anterior communicating artery)

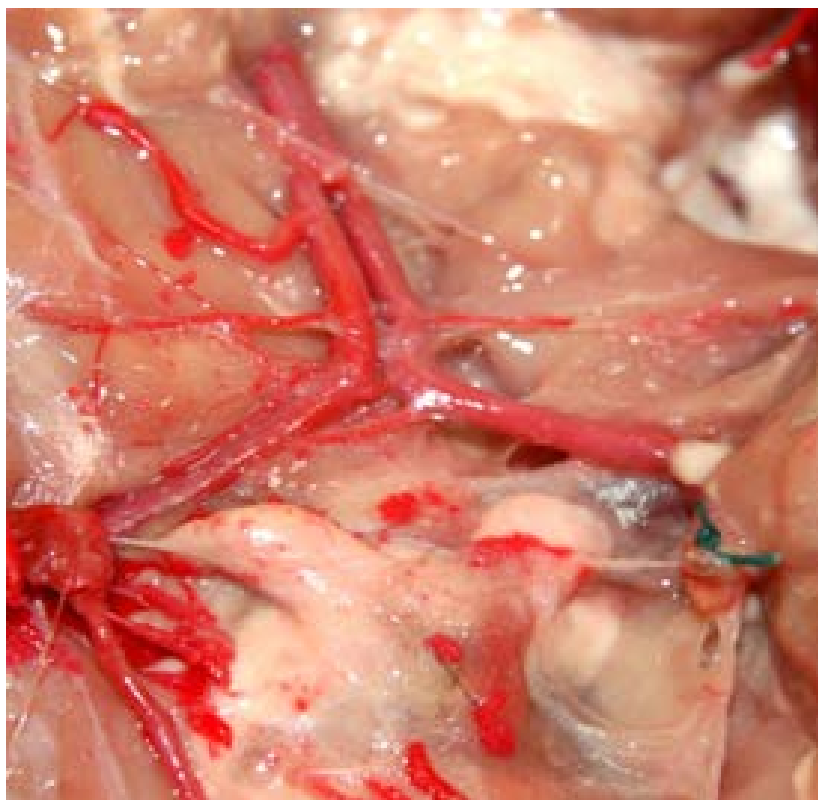

Figure 3 - right RAH originating at ACA A1/A2 junction with a missing $R A H$ on oposite side.

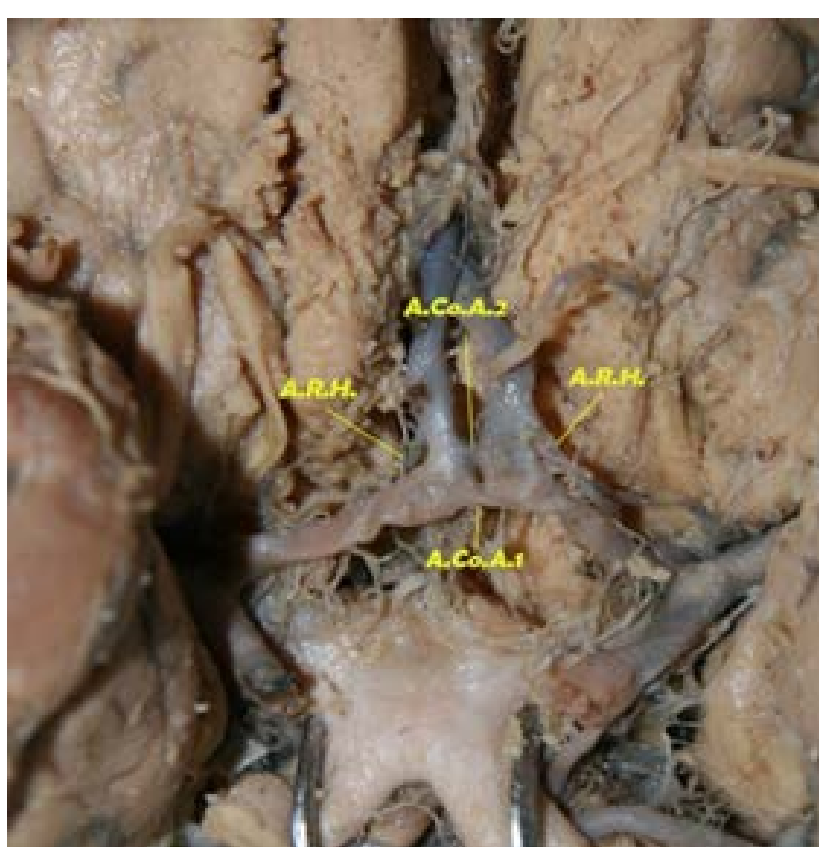

Figure 4 - RAHs originating from ACA A2, simetrically (ARH - recurent artery of Heubner, AcoA - Anterior communicating artery) 
The RAH could not be identified, it was missing in 6 cases, $5.3 \%$, being replaced by a series of small perforating branches with origin from $\mathrm{A} 1, \mathrm{ACoA}$, and even ACI. (Figures 3 and 5)

In 2 cases, $1.8 \%$, RAH is originating from A2 segment thru a common arterial trunk with frontoorbitar artery (Figure 6).

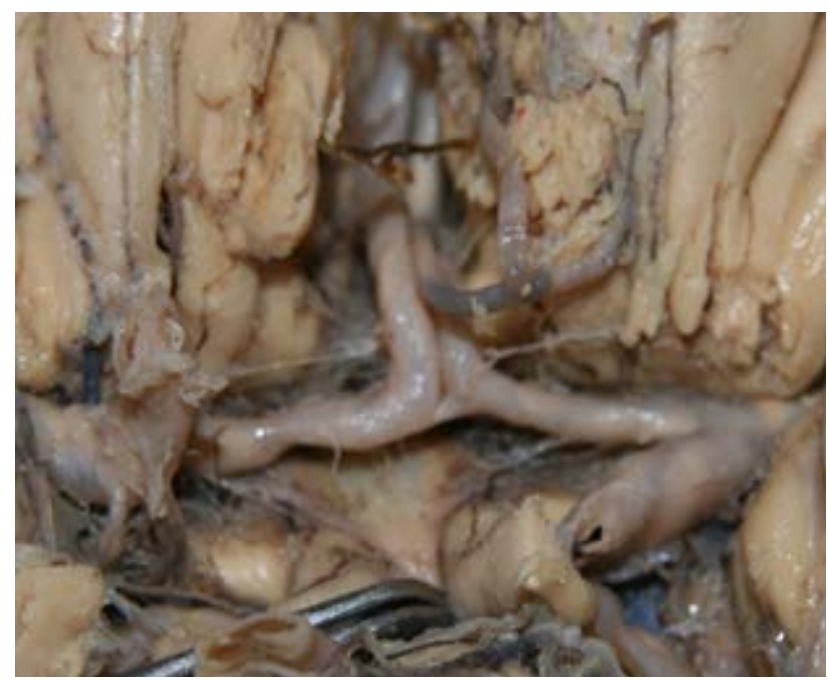

Figure 5 - Billateral absence of RAHs

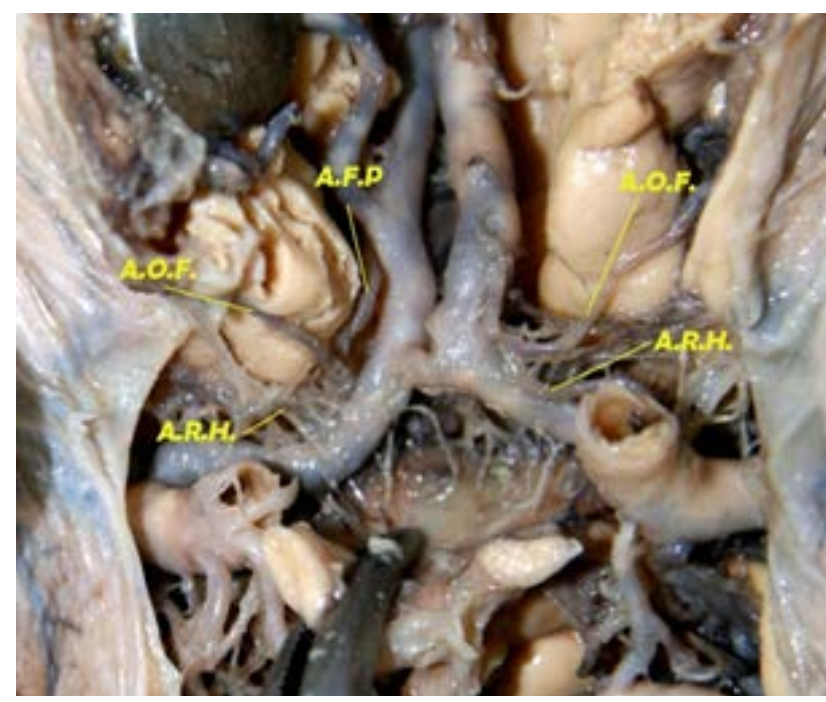

Figure 6 - RAHs originitaing from a common stem with frontoorbitar artery on the left side, and from $A C A A 1$ on the right side (ARH - recurent artery of Heubner, AOF frontorbitar artery, $A F P$ - frontopollar artery)
After originating from its parent artery, most of RAH run parallel to ACA1 segment. The present study found that $74.1 \%$ of RAHs ran anteriorly to A1 (space between ACA and optic nerve), 18.7\% superiorly to A1 (space between ACA and frontal base), and only $3.5 \%$ posteriorly to $\mathrm{A} 1$ (space between ACA and optic tract). The common course of RAHs can be demonstrated along orbital surface of gyrus rectus to medial olfactory striae then run parallel to A1 segment and terminated into medial and lateral parts of anterior perforated substance. The recurrent artery may enter the anterior perforated substance as a single stem or divide into many branches.

The RAH was single in 90 cases, $80.3 \%$ and doubled in 16 cases $14.3 \%$. The artery was bilaterally doubled in 5 brains, $4.5 \%$. We observed unilateral duplication of the vessel in 11 hemispheres, $9.8 \%$. The doubled vessels separately branched from the same ACA segment in 10 hemispheres. The doubled RAHs arose from two portions of ACA in 6 cases (Figure 7, from $\mathrm{A} 2$ and at the junction of ACA-ACoA).

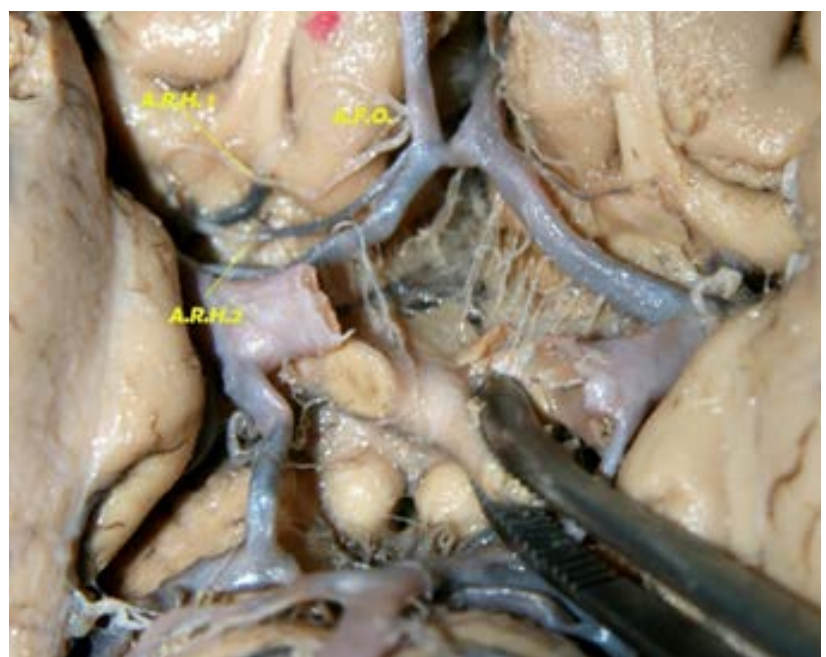

Figure 7 - Two RHA from the right anterior cerebral artery

Right - left symmetry (Fig 4), regarding the origin of RAH was observed in 48 cases, $42.8 \%$.

The diameter of RAH had a minimum value of $0.2 \mathrm{~mm}$ on the right side and a maximum of $1.9 \mathrm{~mm}$ on the left side with a medium value of $0.8 \mathrm{~mm}$. 
About $53 \%$ of RAHs originated at the junction of ACA1/ACA2 or ACoA area. This RAH may adhere to the wall of anterior communicating artery aneurysm. The clipping without dissection of this vessel can cause significant hemiparesis. In $91,5 \%$ of RAHs, excluding the cases where it was missing, had the origin $2 \mathrm{~mm}$ around ACoA.

Although lateral projection from the parent originated from proximal ACA A2 about 78\% Ninety-five percent of the RAHs can be identified within $4 \mathrm{~mm}$ proximal or distal from ACoA[3]. Gomes et al.,1984 reported in 30 unfixed brains that $57 \%$ of RAHs originated from ACA2, 35\% from the junction of the ACA A1/A2, and $8 \%$ from the ACA A1[10]. The observation data from 48 cases of anterior communicating artery aneurysms were described by Aydin et al,1994 [11]. They reported that most of the RAHs originated from the junction of ACA A1/A2 about 58\%, ACA A2 segment about $23 \%$. These findings were similar to the Loukas $M$ series that $62.3 \%$ originated from the junction of ACA A1/A2 and 23.3\% from proximal ACA A2[12].

Our results were compared with other studies published (Table 1). According to the presented study, the junction of ACA A1/A2 was the most common location of the RAH's origin and ACA A2 was the second most common site. artery was very common, the posterior projection can be missed and easily injured during the temporary clipping. Furthermore, this posterior projection vessel may run posterior to the ACA1 in contrast to the more common RAH course, which ran inferior or superior to ACA1. The authors recommended gently dissection on the posterior surface of parent vessel if the common path was not seen

\section{Conclusions}

The RAH is commonly arising from ACAACoA junction. This portion of the circle of Willis is the place of many anatomical variations and

Table 1 RAH origin variability compared with other anatomical studies published.

\begin{tabular}{|l|c|c|c|c|}
\hline \multicolumn{1}{|c|}{ STUDY } & $\begin{array}{c}\text { ORIGIN } \\
\text { FROM ACA A1 }\end{array}$ & $\begin{array}{c}\text { ORIGIN AT } \\
\text { JUNTION OF } \\
\text { ACA A1/A2 }\end{array}$ & $\begin{array}{c}\text { COMMON } \\
\text { ORIGIN } \\
\text { STEM ACA A2 }\end{array}$ & $\begin{array}{c}\text { FRONTORBITAL } \\
\text { ARTERY }\end{array}$ \\
\hline Martinez et al.(13). & 0 & 60,1 & 39,9 & 0 \\
\hline Yasargil(14) & 11,5 & 38 & 25 & 0 \\
\hline Perlmutter et al.(3) & 14 & 8 & 78 & 0 \\
\hline Gomes et al. (10) & 8 & 35 & 57 & 0 \\
\hline $\begin{array}{l}\text { Suazo de la Cruz et } \\
\text { al.(15) }\end{array}$ & 15 & 30 & 39 & 0 \\
\hline Aydin et al.(11) & 4 & 58 & 23 & 0 \\
\hline Loukas et al.(12) & 14.3 & 62.3 & 23.3 & 10 \\
\hline Pai et al.(16) & 10 & 60 & 15 & 1.8 \\
\hline $\begin{array}{l}\text { Gasca- } \\
\text { Gonzales(17) }\end{array}$ & 5 & 44 & 41 & 27.6 \\
\hline Present study & 10.7 & 53.5 & & \\
\hline
\end{tabular}


malformations. The vessel can be absent, single, or multiple, and its diameter is highly variable. The awareness of these distinct anatomical and morphometric variations of the RAH is essential in planning the neurosurgical procedures in the anterior part of the circle of Willis to avoid the unexpected neurological complications.

In conclusion, the RAH should be routinely identified before temporary clipping the parent artery and during clipping ACoA aneurysm to prevent post operative neurological deficit.

Knowing the vascular anatomy and its variation is very important for the neurosurgeons, and neurointerventionists.

\section{References}

1. Haroun R. I., Rigamonti D. \& and Tamargo R. J. (2000). Recurrent artery of Heubner: Otto Heubner's description of the artery and his influence on pediatrics in Germany. Journal of Neurosurgery. 93(6), 1084-1088

2. Loukas M., Louis Jr R. G.\& and Childs R. S. (2006). Anatomical examination of the recurrent artery of Heubner. Clinical Anatomy. 19(1), 2531

3. Perlmutter D. \& Rhoton A.L.Jr. (1976). Microsurgical anatomy of the anterior cerebralanterior communicating-recurrent artery complex. J Neurosurg. 45(3), 259-272.

4. Izci Y., Seckin H., Medow J., Turnquist C. \& Baskaya M. K. (2009). Sulcal and gyral anatomy of the orbitofrontal cortex in relation to the recurrent artery of Heubner: an anatomical study. Surgical and Radiologic Anatomy, 31(6), 439445.

5. Mavridis I. \& Anagnostopoulou S. (2010). Comment on the brain areas whose blood supply is provided by the recurrent artery of Heubner. Surgical and Radiologic Anatomy, 32(1), 91.

6. Tao X., Yu X. J. \& Bhattarai B. et al. (2006). Microsurgical anatomy of the anterior communicating artery complex in adult Chinese heads. Surgical Neurology. 65(2), 155-161.

7. Hernesniemi J., Dashti R. \& Lehecka M. et al. (2008). Microneurosurgical management of anterior communicating artery aneurysms. Surgical Neurology. 70(1), 8-28.

8. Feekes J. A. \& Cassell M. D. (2006). The vascular supply of the functional compartments of the human striatum. Brain. 129(8), 2189-2201.

9. Miller S. P., O'Gorman A. M. \& Shevell M. I. (2000). Recurrent artery of Heubner-infarction in infancy. Developmental Medicine and Child Neurology. 42(5), 344-346.

10. Gomes F, Dujovny M, Umansky F, Ausman JI, Diaz FG \& Ray WJ, et al. (1984). Microsurgical anatomy of the recurrent artery of Heubner. $J$ Neurosurg. 60, 130-9.

11. Aydin I.H., Onder A., Takci E., Kadioglu H.H., Kayaoglu C.R. \& Tuzun Y. (1994). Heubner's artery variations in anterior communicating artery aneurysms. Acta Neurochir. 127, 17-20.

12. Loukas M., Louis R.G. Jr \& Childs R.S. (2006). Anatomical examination of the recurrent artery of Heubner. Clin Anat. 19, 25-31.

13. Martínez BF., Sgarbi LN., Vergara ME., Laza NS., Almirón C. \& Spagnuolo DE. et al. (2003). Anatomía quirúrgica del sector extracerebral de la arteria de Heubner. Arch. Neurocien. 8, 16-22.

14. Yasargil M.G. (1987). Intracranial arteries. (pp. 54-164). In: Yasargil MG. Microneurosurgery. Vol I. New York: Thieme Medical Publishers Inc.

15. Suazo de la Cruz L.E., Garbugino S.L., Moreno G.A. \& Lemme-Plaghos L. (2002). Evaluación anatomoangiográfica del complejo de la arteria comunicante anterior en casos de aneurismas de dicho sector. Rev. Argent. Neurocir. 16, 1-10.

16. Pai S., Kulkarni R., Varma R. (2005). Microsurgical anatomy of the anterior cerebral artery-anterior communicating artery complex: an Indian study. Neurol. Asia. 10, 21-28.

17. Gasca-González O.O., Delgado-Reyes L., PérezCruz J.C. (2011). Microsurgical anatomy of the extracerebral segment of recurrent artery of Heubner in the Mexican population. Cir. Cir. 79, 201-206. 